\title{
Diretores da rede municipal de Fortaleza: achados sobre gestão escolar
}

\author{
Fortaleza municipal network principals: findings on school \\ management
}

\section{Directores de la red municipal de Fortaleza: hallazgos sobre gestión escolar}

\author{
Esmeraldina Januário de Sousa' \\ Rede Pública Municipal de Ensino de Fortaleza, Professora e Supervisora escolar. \\ http://orcid.org/0000-0003-3349-0838 \\ Eloisa Maia Uidal² \\ Universidade Estadual do Ceará, Professora associada. \\ https://orcid.org/0000-0003-0535-7394
}

Resumo: Este artigo analisa aspectos relacionados à gestão escolar tendo como referência entendimentos sobre a gestão democrática e participativa e algumas questões presentes nos questionários contextuais do Diretor e do Professor do Sistema de Avaliação da Educação Básica (Saeb), aplicados pelo Instituto Nacional de Estudos e Pesquisas Educacionais Anísio Teixeira (Inep) em 2017, tendo como recorte a rede municipal de Fortaleza, capital do Ceará. São dados de 244 diretores e 3.351 professores, sendo 1.805 do $5^{\circ}$ ano e 1.546 do $9^{\circ}$ ano, que foram descompactados em planilha do Microsoft Excel e trabalhados com o uso de soma de variáveis, com estatísticas descritivas e, em alguns casos, com análise de correlação. 0s resultados mostram que mais de $3 / 4$ das escolas possuem Conselho Escolar composto por todos os segmentos da comunidade; cerca de $2 / 5$ dos diretores afirmam haver interferências externas na gestão; e 4/5 estão frequentemente discutindo com os professores medidas para melhorar o ensino e a aprendizagem. Os professores possuem uma visão positiva sobre a gestão escolar na dimensão pedagógica, administrativa e nas relações interpessoais, no entanto, quando analisadas respostas de diretores e professores a uma mesma questão, os resultados são discrepantes, apontando para a necessidade de investigar tais contradições.

Palavras-chave: Gestão democrática e participativa. Questionários contextuais do Saeb; Gestão escolar. Rede municipal. Fortaleza.

\footnotetext{
Especialista em Metodologia do Ensino Fundamental e Médio pela Universidade Vale do Acaraú; mestranda no Programa de Pós Graduação em Educação da Universidade Estadual do Ceará.

2 Doutora e Mestre em Educação pela Universidade Federal do Ceará.
} 
Abstract: This paper analyzes aspects related to school management with as reference understandings about democratic and participatory management and some issues present in the questionnaires Evaluation of Basic Education (Saeb), applied by the National Institute of Educational Studies Teixeira (Inep) in 2017, having as clipping the municipal network of Fortaleza, capital of Ceará. They are data of 244 directors and 3.351 teachers being 1.805 of the 5th years and 1.546 of the 9th years, which were decompressed in Microsoft Excel spreadsheet and worked with use of sum of variables, descriptive statistics and, in some cases, with correlation analysis. The results show that more than 3/4 of the schools has School Council composed of all segments of the community; about 2/5 of the directors states there are external interference in management and 4/5 is frequently discussing with teachers measures to improve teaching and learning. Teachers have a positive view on school management in the pedagogical, administrative and interpersonal dimension, however, when analyzing responses from directors and teachers to the same question, the results are inconsistent, pointing to the need to investigate such contradictions.

Keywords: Democratic and participatory management. Saeb contextual questionnaires. School management. Municipal network. Fortaleza.

Resumen: Este artículo analiza aspectos relacionados con la gestión escolar teniendo como referencia entendimientos sobre la gestión democrática y participativa y algunas cuestiones presentes en los cuestionarios contextuales del Director y del Profesor del Sistema de Evaluación de la Educación Básica (Saeb), aplicado por el Instituto Nacional de Estudios e Investigaciones Educativas Anísio Teixeira (Inep) en 2017, teniendo como recorte la red municipal de Fortaleza, capital de Ceará. Son datos de 244 directores y 3.351 profesores siendo 1.805 del $5^{\circ}$ año y 1.546 del $9^{\circ}$ año, que fueron descompuestos en hoja de cálculo de Microsoft Excel y trabajados con uso de suma de variables, estadísticas descriptivas, en algunos casos, con análisis de correlación. Los resultados muestran que más de 3/4 de las escuelas tiene Consejo Escolar compuesto por todos los segmentos de la comunidad; cerca de 2/5 de los directores afirma haber interferencias externas en la gestión y 4/5 está a menudo discutiendo con los profesores medidas para mejorar la enseñanza y el aprendizaje. Los profesores tienen una visión positiva sobre la gestión escolar en la dimensión pedagógica, administrativa y en las relaciones interpersonales, sin embargo, cuando analizan respuestas de directores y profesores a una misma pregunta, los resultados son divergentes, lo que indica la necesidad de investigar tales contradicciones.

Palabras clave: Gestión democrática y participativa. Cuestionarios contextuales de Saeb. Gestión escolar. Red municipal. Fortaleza.

Recebido em 10 de outubro de 2019

Aceito em 12 de junho de 2020

Publicado em 28 de agosto de 2020 


\section{INTRODUÇÃO}

As discussões sobre a gestão nas escolas públicas perpassam as últimas três décadas do pensamento educacional no Brasil (SOUZA; PIRES, 2018; VIEIRA; VIDAL, 2015, 2019; STÊNICO; ADAM; PAES, 2015). A Lei de Diretrizes e Bases da Educação (LDB n. 9.394/96) estabelece os princípios da gestão da educação que consiste na participação da comunidade e dos profissionais da escola e delega aos sistemas de ensino a implementação da gestão democrática e participativa (Art. 14). Como não existe um normativo nacional sobre as condições mínimas que orientem o modelo proposto, coube aos estados e municípios, a partir de critérios próprios, definir seus entendimentos.

Assim, a gestão democrática e participativa adquire um caráter polissêmico que abriga desde processos diversos a respeito da escolha dos diretores escolares (VIEIRA; VIDAL, 2015; 2019); mecanismos de implementação da gestão escolar, que asseguram maior ou menor liberdade de ação aos gestores, graus distintos de autonomia administrativa e financeira, e autoria ou não do projeto político-pedagógico da escola.

Este artigo analisa algumas questões presentes nos questionários contextuais do Diretor e do Professor do Sistema de Avaliação da Educação Básica (Saeb), aplicados pelo Instituto Nacional de Estudos e Pesquisas Educacionais Anísio Teixeira (Inep) em 2017, quando da realização das avaliações de larga escala bianuais, tendo como recorte a rede municipal de Fortaleza, capital do Ceará. Os questionários contextuais são aplicados junto a alunos, professores e diretores e tem como objetivo coletar informações que venham a orientar as políticas públicas. ${ }^{3}$ Os microdados foram obtidos no site do lnep e descompactados para uso em planilha do Microsoft Excel, que foi trabalhada por meio de soma de variáveis e estatísticas descritivas e, em alguns casos, com análise de correlação.

0 interesse pela rede municipal ${ }^{4}$ de Fortaleza se justifica pelo fato de, nos últimos anos, ter ocorrido substancial melhoria dos resultados educacionais captados pelo Índice de Desenvolvimento da Educação Básica (ldeb) e também pelas mudanças implementadas na gestão educacional do Município a partir de 2013, quando o grupo político eleito para a Prefeitura pertence ao mesmo matiz político do Governo do Estado. Esse momento é marcado por mudanças na gestão da máquina pública, que se alinha ao modelo de Gestão por Resultados (GpR) que vem sendo implementado pelo Governo do Estado do Ceará desde 2004 (HOLANDA, 2006), inclusive no campo da educação, que passa a incorporar mecanismos

3 Da avaliação do Saeb de 2017 participaram 73.674 escolas, sendo que 71.589 responderam ao questionário e 69.676 são diretores de escolas públicas; no caso dos professores, foram 753.668 participantes dos $5^{\circ}$ e $9^{\circ}$ anos que atuam nas disciplinas de Língua Portuguesa e Matemática, sendo 740.260 das escolas públicas.

4 Segundo os microdados do Saeb 2017, participaram 246 escolas, mas dois dos questionários do diretor não foram preenchidos; no caso dos professores, o total foi de 3.954 participantes, sendo que 603 não preencheram o questionário. 
de administração, monitoramento e avaliação das iniciativas educacionais nas escolas, à semelhança do modelo estadual.

0 estudo utiliza dados de 244 diretores e 3.351 professores, sendo 1.805 do $5^{\circ}$ ano e 1.546 do $9^{\circ}$ ano, que responderam aos questionários contextuais do Saeb 2017 . Foram identificadas nos questionários perguntas que, de alguma forma, tivessem relação com a atuação da equipe gestora em torno de estratégias adotadas na gestão escolar. No questionário do diretor, das nove questões encontradas, quatro integram o bloco temático Características da Equipe Escolar (Q.29, Q.30, Q.31 e Q.32); uma, o bloco temático Políticas, ações e programas escolares (Q.44); e quatro, o bloco temático Visão sobre os problemas da escola e dificuldade de gestão (Q.77 a Q.80). Com relação ao questionário do professor, detectaram-se 14 questões que se relacionam com a gestão escolar, encontradas no bloco Integração da Equipe Escolar (Q.51, Q.52, Q.53, Q.58 a Q.68). Do total das questões analisadas nos dois instrumentos, duas são comuns aos dois questionários ${ }^{5}$ e serão analisadas em uma seção específica.

Este artigo contém, além desta Introdução, quatro seções e mais as Considerações finais. A primeira seção é dedicada a explicitar o entendimento sobre gestão democrática e participativa à luz de diversos autores; na segunda, são apresentados e analisados os dados relativos à visão dos diretores sobre aspectos associados ao modelo de gestão implementada nas escolas; a terceira seção apresenta dados coletados no questionário do professor relacionados a aspectos envolvendo a equipe escolar; na quarta, são exploradas as duas questões presentes nos dois questionários, cotejando as respostas dos diretores com as dos professores. Finalmente, as considerações finais destacam a importância do trabalho com os microdados dos questionários contextuais como forma de identificar elementos e aspectos que podem contribuir para a elaboração de políticas públicas.

\section{A GESTÃO DEMOCRÁTICA E PARTICIPATIUA NA EDUCAÇÃO BRASILEIRA}

Estudos nacionais e internacionais que apresentam e discutem resultados e perspectivas teóricas e conceituais de pesquisas da área sobre o tema da gestão escolar têm destacado a interrelação entre gestão escolar, liderança do diretor e resultados educacionais (VIEIRA; VIDAL, 2019; OLIVEIRA; CARVALHO, 2018; MURILLO, 2018; WEINSTEIN; MUÑOZ; HERNÁNDEZ, 2014; LEITHWOOD, 2009; DAY et al., 2009; WEINSTEIN; MUÑOZ, 2019; CANO et al., 2006). Outros estudos têm discutido e aprofundado questões relativas ao perfil dos gestores escolares no Brasil

\footnotetext{
5 Nesse caso, Q.31 e Q.32 do questionário do diretor e Q.51 e Q.52 do questionário do professor.
} 
(VIEIRA; VIDAL, 2014; OLIVEIRA; GIORDANO, 2018; RIBEIRO, 2017) e abordado a gestão democrática (SOUZA, 2019; VIEIRA; VIDAL, 2015; BÄCKMAN; TRAFFORD, 2007; MENDIZÁBAL et al., 2016; OECD, 2014).

A Constituição Federal (CF) de 1988 expressa os princípios e valores subjacentes à manutenção, à proteção e ao desenvolvimento da democracia no Brasil e estabelece no inciso Vl, do Art. 206, o princípio da "gestão democrática do ensino público" como base para o ensino ministrado (BRASIL, 1988). A partir de um olhar mais aprofundado, constata-se que a gestão democrática é adotada pelo Estado para alcançar seus objetivos estratégicos, e a participação social termina sendo proposta por um Estado fortemente marcado por ordenamentos patrimonialistas (MENDONÇA, 2001), o que é contraditório, posto que "[...] a democracia, como qualquer sonho, não se faz com palavras desencarnadas, mas com reflexão e prática." (FREIRE, 1997, p. 61).

Nesse percurso, emerge no país um modelo baseado nos princípios da Nova Gestão Pública (DALE, 2010; ROSAR, 2015; PEREIRA, 2017), em que o gerencialismo assume protagonismo, considerando a busca por eficiência, eficácia e produtividade as novas marcas de referência das políticas públicas. Cabral Neto e Castro (2007, p. 43) argumentam que o novo modelo de gestão se apresenta com (re)significação de vários termos importantes, na medida em que é subtraído o seu sentido político, dentre eles a participação, a qual "[...] é encarada essencialmente como uma técnica de gestão e, portanto, um fator de coesão de consenso." Dessa forma, não existe na instituição escolar espaço para o conflito, para o debate e, tampouco, para o confronto de ideias. Ou seja, a filosofia de liderança da Nova Gestão Pública (NGP) contradiz claramente o tipo de gestão tradicionalmente associada à administração pública (JARL; FREDRIKSSON; PERSSON, 2012, p. 1). Consequentemente, como apontam Araújo e Castro (2011, p. 93),

\footnotetext{
[...] é possivel evidenciar que a escola pública vem sendo alvo de uma cultura organizacional nos moldes empresariais que, ao invés de estimular a mobilização política na busca da redistribuição do poder, próprio da gestão democrática, é capaz de obstruir a participação ativa e efetiva de embates e conflitos, por uma legitimada, em que os atores sociais participam, apenas, como coadjuvantes do processo educativo.
}

Assim, a partir da intencionalidade apontada nos normativos legais, "modelos" de gestão democrática e participativa vão se instituindo na prática e adquirindo novos contornos, como apontam Cabral Neto e Castro (2007) e Araújo e Castro (2011). No caso do Ceará e da rede municipal de Fortaleza, em específico, a implementação de um modelo de gestão pública está focalizada em resultados que, conforme aponta Alcantara (2006, p. 7), "mais do que uma rotina de trabalho, a Gestão por Resultados é um movimento contínuo de construção de 
uma cultura de governo onde o que importa não é o que se faz, mas o que se consegue alcançar."

Assim, o modelo adotado escamoteia o sentido político, valorizando a "coesão do consenso" e inibindo, muitas vezes, o confronto de ideias. Nesse caso, o que importa é o fim, consubstanciado num resultado, numa meta. 0 que se observa é que, a partir de 2013, o fato de os governos da prefeitura e o estado estarem politicamente alinhados possibilitou uma parceria público-pública na política de desenvolvimento social, especialmente na educação, introduzindo a gestão por resultados na gestão escolar da capital.

Para Dourado (2013, p. 97-98), a gestão democrática deve ser entendida como:

[...] processo de aprendizado e de luta política que não se circunscreve aos limites da prática educativa mas vislumbra, nas especificidades dessa prática social e de sua relativa autonomia, a possibilidade de criação de canais de efetiva participação e de aprendizado do "jogo" democrático e, consequentemente, do repensar das estruturas de poder autoritário que permeia as relações sociais e, no seio dessas, as práticas educativas.

Ou seja, há um entendimento de que a gestão da educação numa perspectiva democrática vai além de administrar sistemas ou escolas, e está intimamente ligada aos embates travados no âmbito das relações sociais e políticas, pois se trata de um processo político coletivo que envolve princípios de democracia, de direitos humanos e, prioritariamente, o conceito de participação, abrangendo as políticas educativas, os sistemas ou redes educacionais e as instituições de ensino. A gestão democrática adquiriu diversos significados em diferentes contextos políticos (FORNO; FERREIRA; MARKOWICZ, 2012; ARAÚJ0, 2009; LIMA, 2013; CERQUEIRA, 2000; FUJITA, 2015), no entanto é consenso que a participação tem papel central na formação de uma cidadania democrática.

Silva (2001, p. 56) destaca que existem, a priori, duas dimensões (interna e externa) em que se baseiam as características de uma gestão democrática, sendo que "a dimensão interna diz respeito à organização da escola em si e, a dimensão externa, à sua incorporação ao Estado e à sua inserção no contexto de uma sociedade capitalista." A dimensão interna é traduzida pela organização e funcionamento da instituição escolar, enquanto a dimensão externa se relaciona com a função social da escola, a produção e a disseminação do conhecimento.

Esses fatores juntos vão dar a tônica de quão democrática será a gestão de cada escola, pois, como afirma Gadotti (2014, p. 1), "a gestão democrática não é só um princípio pedagógico", mas o produto das diferentes funções sociais atribuídas à escola e a consequência das tendências e modelos pedagógicos que foram se alternando no Brasil, 
bem como das forças de conflito traduzidas, em especial, pelo liberalismo e pelo socialismo, responsáveis pela manutenção ou transformação social. Em outras palavras, um jogo entre estrutura e conjuntura.

Nardi e Boiago (2018) trazem à tona a ideia de que uma gestão participativa pode abrir e fortalecer outras instâncias de participação operacional com funções definidas e canalizar o envolvimento de membros da comunidade por meio de instrumentos de ação coletiva dentro da escola, como o Conselho Escolar. Este possibilita uma maneira de compartilhar o poder de decisão das instituições de ensino por meio da participação ativa nos planejamentos e nas resoluções acerca das necessidades que a escola possui. A Associação de Pais e Mestres, - Grêmio Estudantil e outros grupos que trabalham de acordo com os preceitos da gestão democrática são organizações que podem fortalecer a participação. No entanto, o fato de existirem essas instâncias e a garantia de condições adequadas, como a disponibilidade de tempo e espaço, não assegura a participação de todos os atores da comunidade escolar ou que eles possam atuar de diferentes formas.

Espera-se que o diretor e sua equipe gestora não apenas informem as decisões tomadas ou consultem os diferentes atores antes que eles mesmos as tomem, mas que recebam propostas e definam conjuntamente as decisões finais. De acordo com Rodríguez-Ruiz, Martinez-Gonzalez e Rodrigo Lopez (2016, p. 81), "isso requer compartilhar informações, chegar a acordos mútuos sobre os papéis a serem desempenhados, assumir responsabilidades conjuntas e manter relacionamentos baseados em respeito, lealdade, confiança e honestidade." Barroso (2003) e Carvalho (2009) apresentam os seguintes fatores como direcionadores do processo de participação na escola: a) ação cooperativa promovendo uma cultura de reflexão; b) clima de confiança; c) valorização das capacidades e aptidões dos participantes; d) trabalho de equipe; e) relação da escola com a família e a comunidade; e f) a escola como espaço de convivência.

\section{UM OLHAR SOBRE O QUE DIZEM OS DIRETORES ACERCA DA GESTÃO ESCOLAR EM FORTALEZA, CE}

A Cidade de Fortaleza é constituída por 119 bairros (SECRETARIA MUNICIPAL DE DESENVOLVIMENTO ECONÔMICO, 2014), que possuem uma população estimada de 2.669 .342 habitantes (IBGE, 2019). Apresenta uma complexa rede escolar constituída de 291 estabelecimentos de ensino públicos municipais, que abrigam uma matrícula de 214.099 alunos desde a educação infantil (creche e pré-escola), ensino fundamental e educação de jovens e adultos (INEP, 2019). Em 2017, das 222 escolas que ofertavam anos iniciais do ensino 
fundamental, $183(82,4 \%)$ participaram do Saeb, e das 134 escolas que oferecem anos finais do ensino fundamental, 106 (79,1\%) participaram do exame. No período 2005-2017, o ldeb dos anos iniciais da rede municipal cresceu $87,5 \%$, e nos anos finais o crescimento foi de $96,0 \%$, o que destaca o seu desempenho em relação às demais capitais do país.

A gestão da educação pública municipal está a cargo do Sistema Municipal de Ensino de Fortaleza (SMEF), criado pela Lei Municipal n. 9.317/2007 (FORTALEZA, 2007), cujos órgãos devem exercer as funções de planejamento, organização, implantação e execução de políticas e planos educacionais, em consonância com as diretrizes e os planos nacionais e estaduais de educação. A organização, assim como a natureza das atribuições do SMEF, inspira-se nos princípios da gestão democrática, uma vez que preceitua a interrelação entre as instâncias de participação que a compõem: Secretaria Municipal de Educação; Conselho Municipal de Educação (CME); Escolas Públicas Municipais de Ensino Fundamental; Centros de Educação Infantil (CEI) mantidos pelo Poder Público Municipal e Creches Parceiras (convênios com a iniciativa privada) como prerrogativa de sua atuação.

A gestão escolar da rede municipal de ensino de Fortaleza está regulamentada por meio da Lei Complementar n. 169/2014, que dispõe sobre a gestão democrática e participativa a partir de alguns princípios norteadores, entre eles:

I. participação da comunidade na definição e na implementação de decisões pedagógicas, administrativas e financeiras, por meio de órgãos colegiados;

II. $\quad$......

III. autonomia das unidades escolares, nos termos da legislação, nos aspectos pedagógicos, administrativos e financeiros;

IV. transparência da gestão da escola pública de Fortaleza, nos aspectos pedagógicos, administrativos e financeiros;

V. $\quad$.......

VI. democratização das relaç̃̃es pedagógicas e de trabalho, criação de ambiente seguro, propicio ao aprendizado e a construção do conhecimento;

VII. ......

VIII. escolha de Diretor Escolar, Vice-Diretor Escolar, Superintendente Escolar, Secretario Escolar e Coordenador Pedagógico através de Seleção Pública, garantida ampla publicidade.

No que se refere à escolha dos gestores da rede pública municipal de Fortaleza, analisaram-se as respostas à questão $Q .14$ do questionário do Diretor 2017, que indaga sobre como esses gestores assumiram a direção escolar. 0s dados mostram que 66,8\% informam que assumiram por meio de processo seletivo, 20,1\% afirmam ter se submetido a processo seletivo seguido de indicação, e 9,4\% afirmam ter assumido o cargo por meio de concurso público. Considerando que não existe a modalidade de concurso público para ocupação de 
cargo de direção escolar, os que indicaram essa resposta estão se referindo à seleção pública estabelecida na legislação. Assim, depreende-se que $76,2 \%$ dos diretores restringiram a informação à primeira etapa do processo seletivo, uma vez que a segunda etapa consiste, de fato, na indicação para o cargo, como sendo uma prerrogativa da Secretaria Municipal de Educação de Fortaleza. Assim, as respostas expressam que o princípio da escolha de gestores apontado na legislação vigente está sendo observado, embora a Lei n. 13.005/2014, que estabelece o Plano Nacional de Educação 2014-2024, preveja na meta 19 "assegurar condições, no prazo de 2 (dois) anos, para a efetivação da gestão democrática da educação, associada a critérios técnicos de mérito e desempenho e à consulta pública à comunidade escolar, no âmbito das escolas públicas [..." (BRASIL, 2014, grifo nosso).

A presença do Conselho Escolar é uma recomendação presente na LDB de 1996 (Art. 14, inciso II) e no caso da rede municipal de Fortaleza, considerado um órgão de controle social (FORTALEZA, 2015, p. 47) e um requisito para assegurar a gestão democrática e participativa nas escolas. De acordo com Alves (2005, p. 26),

\footnotetext{
0 Conselho de Escola - concebido como um espaço que proporciona as livres manifestações de ideias e a geração de novas propostas vinculadas às demandas sociais - poderá ser um elemento facilitador na vivência da democracia na gestão escolar. Nesse sentido, é um dos principais instrumentos de democratização da escola, devendo ser visto não como mais um órgão escolar, mas como um modo de conceber e praticar a educação.
}

No questionário do Diretor, a pergunta $Q .29$ diz respeito à frequência com que o Conselho Escolar se reúne durante o ano, e o Gráfico 1 apresenta os dados referentes às respostas dos diretores em 2017.

Gráfico 1 - Presença do Conselho escolar e frequência de reuniões por ano, 2017

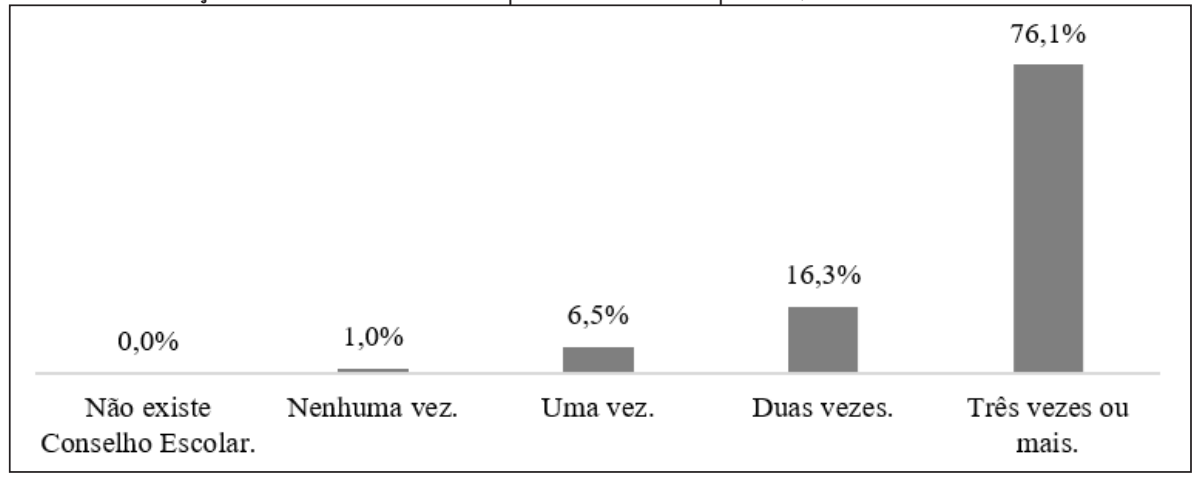

Fonte: os autores. 
0s diretores informam que 76,1\% das escolas reúnem o Conselho Escolar três ou mais vezes por ano, enquanto $16,3 \%$ das escolas o reúnem duas vezes, e $6,5 \%$, apenas uma vez. 0 que se constata é que mais de $3 / 4$ das escolas reúnem seus Conselhos Escolares três vezes ou mais por ano.

Apoiado em Silva (2001), é possível afirmar que a presença do Conselho Escolar é parte da dimensão interna da escola, e a frequência com que se reúne dá pistas sobre o grau de participação operacional (NARDI; BOIAG0, 2018). No caso da rede municipal de Fortaleza, a legislação em vigor (Lei-Complementar n. 169), em seu Art. 21, recomenda que "o Conselho Escolar se reunirá, ordinariamente, uma vez por mês e, extraordinariamente, a qualquer tempo, por convocação [...]" (FORTALEZA, 2014). Assim, os dados apresentados mostram que tal legislação não está sendo cumprida.

A existência dos Conselhos Escolares tem associação com os recursos financeiros advindos dos governos federal (PDDE) e municipal (PMDE), uma vez que em ambos os casos há a exigência de criação de Unidade Executora de Recursos Financeiros (UERF) na escola para o gerenciamento e definição de aplicação dos valores recebidos. Isso pode ser considerado uma forma de compartilhar o poder de decisão ou funcionar apenas como um mecanismo de gestão para legitimar consensos, como apontam Cabral Neto e Castro (2007).

Sobre a composição dos Conselhos Escolares, também prevista na Lei n. 9394/96, os diretores responderam conforme apresentado no Gráfico 2.

Gráfico 2 - Composição do Conselho Escolar

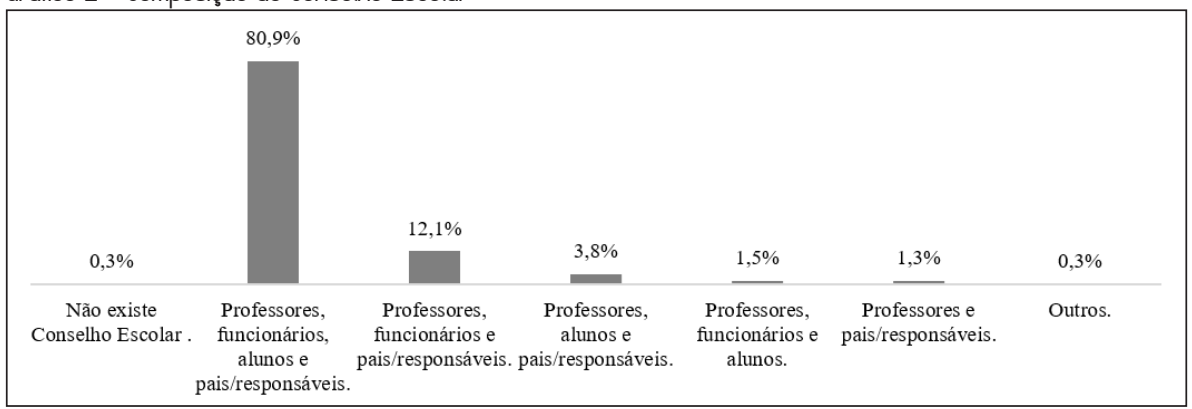

Fonte: os autores.

As informações obtidas a partir do questionário mostram que $80,9 \%$ das escolas possuem um Conselho Escolar composto por: professores, funcionários, alunos e pais/ responsáveis; १२,१ das escolas não incluem os alunos nesse órgão; e 3,8\% não incluem os funcionários. Ou seja, em $4 / 5$ da rede municipal de ensino de Fortaleza predominam 
Conselhos Escolares constituídos por representantes de todos os segmentos da comunidade escolar e em mais de $3 / 4$ eles se reúnem três vezes ou mais por ano para deliberar sobre assuntos atinentes às diversas dimensões da gestão escolar.

Na visão de Drescher (2014, p. 42), a "implantação de um Conselho Escolar na escola constitui-se em um artifício valioso na integração dos segmentos escolares." Mas somente sua existência não basta. Porque "o conselho escolar é fomentado e viabilizado como colegiado instituído para possibilitar a desconcentração de um poder autoritário." (VEIGA, 2009 , p. 6). A representatividade do Conselho Escolar possibilita "ouvir a pluralidade das vozes, ajuda o dirigente a acertar mais e permite, tanto no cotidiano da gestão quanto na formulação de planos, programas e projetos, focar sua ação na realização dos objetivos [...]" (BORDIGNON, 2009, p. 42). Ou seja, nos Conselhos Escolares, enquanto espaços públicos, as demandas são organizadas, articuladas, provocam mudanças e definem ações para a comunidade escolar. No caso das escolas da rede municipal de Fortaleza, a constituição dos Conselhos Escolares possui representatividade, como informam os diretores, no entanto a pouca frequência de reuniões pode apontar para uma existência mais burocrática.

Quando indagados sobre com que frequência discutem medidas com os professores com o objetivo de melhorar o ensino e a aprendizagem dos alunos (Q.44), os diretores se posicionaram de acordo com os dados apresentados no Gráfico 3.

Gráfico 3 - Frequência com que a direção discute medidas com os professores para melhorar o ensino e aprendizagem dos alunos

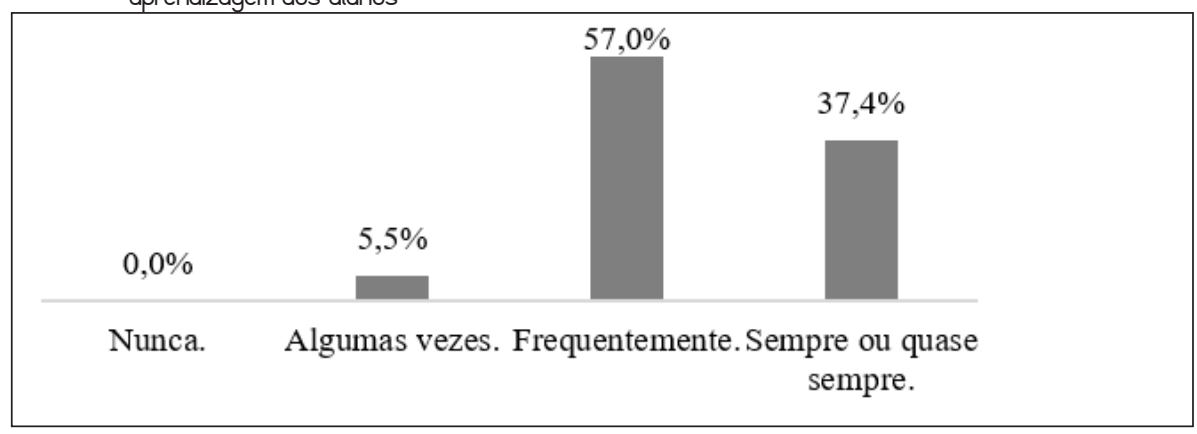

Fonte: os autores.

0 que se observa é que a dimensão pedagógica tem ocupado mais tempo na agenda dos diretores (94,7\%), fato que pode estar associado à implementação de uma robusta política de accountabilility que se utiliza de mecanismos de high stakes, apoiada em avaliação de larga escala aplicada anualmente e de forma censitária a partir de testes de Língua 
Portuguesa e de Matemática a alunos do $2^{\circ}, 5^{\circ}$ e $9^{\circ}$ anos do ensino fundamental. ${ }^{6}$ Esse modelo, implementado pelo governo do Estado tem induzido as redes municipais de ensino a alinharem suas políticas educacionais aos interesses do estado, especialmente depois da criação de mecanismos de vinculação do repasse da cota-parte do ICMS $^{7}$ aos resultados de desempenho dos alunos.

0 bloco de questões 77 a 80 (Gráfico 4) diz respeito às condições existentes para o exercício do cargo de diretor em escolas e expressa indicadores sobre a autonomia administrativa da gestão escolar e o apoio que esta recebe considerando interferências externas na gestão, apoio de instâncias superiores, rede de colaboração e apoio da comunidade.

Gráfico 4 - Condições existentes para o exercício do cargo de diretor

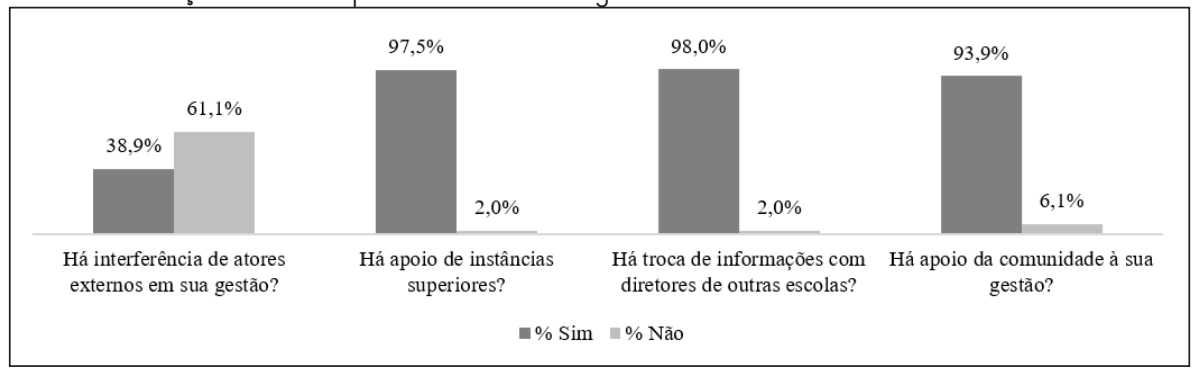

Fonte: os autores.

0s dados mostram que 38,9\% dos diretores afirmam haver interferência de atores externos à sua gestão, enquanto 97,5\% informam existir apoio de instância superior; 98,0\% dizem que há trocas de informações com diretores de outras escolas, e 93,9\% relata haver apoio da comunidade à sua gestão. Embora o questionário do Saeb não explicite o que vêm a ser os "atores externos", não estão fora de cogitação interferências que a secretaria municipal de educação pode realizar em razão, inclusive, da pouca autonomia financeira da escola.

6 Sistema Permanente de Avaliação da Educação Básica (Spaece) é uma avaliação de larga escala estadual, aplicado anualmente às escolas municipais que possuem $2^{\circ}, 5^{\circ}$ e $9^{\circ}$ anos do ensino fundamental e têm associados a seus resultados mecanismos de premiação e bônus que incidem sobre municípios, escolas e equipes educacionais.

7 Os critérios para distribuição dos $25 \%$ do Imposto sobre Circulação de Mercadorias e Prestação de Serviços (ICMS) aos municípios, por meio da Lei $n$. 14.023, de 17 de dezembro de 2007, que no seu art. $1^{0}$ informa o novo modelo para cálculo: $\|$ - १८\% (dezoito por cento) em função do Índice Municipal de Qualidade Educacional de cada município, formado pela taxa de aprovação dos alunos do $1^{\circ}$ ao $5^{\circ}$ ano do ensino fundamental e pela média obtida pelos alunos de $2^{\circ}$ e $5^{\circ}$ anos da rede municipal em avaliações de aprendizagem (CEARÁ, 2007). 
No tocante ao apoio da comunidade à gestão escolar, para Pena e Soares (2014, p. 45),

a gestão escolar é mais eficaz quando a liderança é exercida de forma colaborativa, sustentada a partir de metas claras e objetivos institucionais definidos em comum acordo com todos da escola. 0 diretor, nesse caso, é o agente catalizador das lideranças em direção a proposições compartilhadas.

A análise realizada mostra que todas as escolas cujos diretores responderam ao questionário possuem Conselho Escolar, com 4/5 deles constituídos de professores, funcionários, alunos e pais/responsáveis que se reúnem, em grande parte das escolas, três ou mais vezes por ano. Mostra, também, que a dimensão pedagógica tem assumido protagonismo na agenda da grande maioria dos diretores e que 38,9\% deles reconhecem que há interferência de atores externos à sua gestão.

\section{UM OLHAR SOBRE O QUE DIZEM OS PROFESSORES}

No questionário contextual do professor do Saeb 2017, o bloco Integração da Equipe Escolar é composto por 19 questões, das quais duas também estão presentes no questionário do diretor e serão objeto de análise no próximo tópico. As demais questões procuram investigar aspectos relacionados à frequência com que determinados eventos acontecem na escola em que trabalham. 0 Gráfico 5 apresenta dados para Q.53 a Q.57, respondidas pelos professores.

Gráfico 5 - Na escola, com que frequência você ... ?

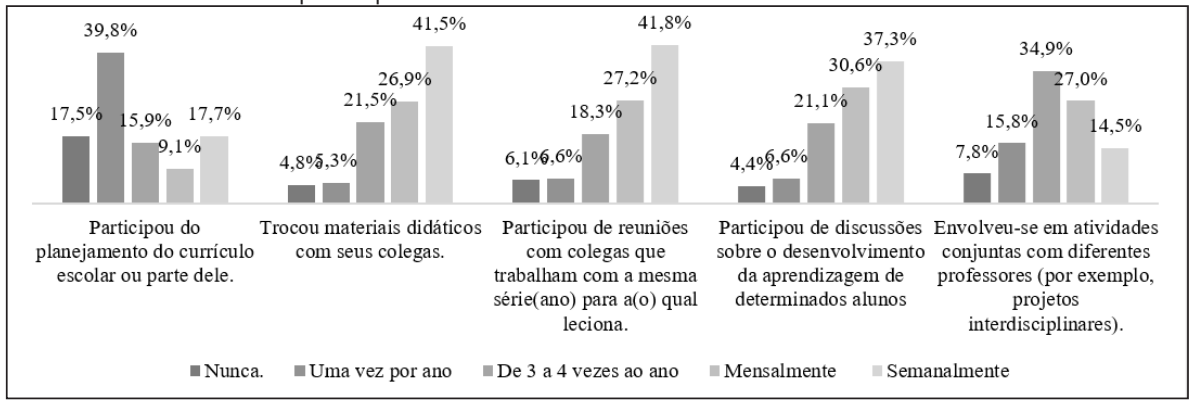

Fonte: os autores. 
Os dados relativos às questões do Gráfico 5 mostram que:

a) enquanto $39,8 \%$ dos professores afirmam que participam do planejamento do currículo uma vez por ano, 17,5\% informam nunca participar. Ou seja, $57,3 \%$ dos docentes têm pouca ou nenhuma participação no planejamento do currículo escolar;

b) por outro lado, $41,5 \%$ dos docentes afirmam realizar, semanalmente, trocas de materiais didáticos com os colegas, e $26,9 \%$ o fazem mensalmente, o que aponta para níveis de socialização do trabalho escolar bastante expressivos;

c) em valores bastante semelhantes (41,8\% e $27,2 \%$ ), os professores informam participar de reuniões com colegas que trabalham com o mesmo ano escolar. Faz parte da rotina escolar, inclusive presente em normativos da SME, que 1/3 da carga horária docente, previsto pela Lei do Piso Nacional do Magistério, para planejamento, seja contemplada com carga horária para planejamento coletivo de docentes do mesmo ano escolar, da mesma disciplina etc.;

d) as preocupações relacionadas ao desenvolvimento da aprendizagem têm mobilizado os docentes de modo a $67,9 \%$ deles participarem de discussões mensais ou semanais. Essa preocupação, como foi observado no Gráfico 3, é pauta também dos diretores;

e) $\circ$ envolvimento com projetos multidisciplinares que mobiliza diferentes docentes ainda tem pouca frequência, segundo os professores que responderam ao questionário. Para $58,8 \%$ deles, esse tipo de iniciativa ocorre de três a quatro vezes por ano ou menos. Isso tem implicação direta sobre iniciativas curriculares envolvendo projetos interdisciplinares pouco frequentes na cultura escolar.

0s Gráficos 6, 7 e 8 dizem respeito à relação dos professores com a direção da escola. No Gráfico 6 encontram-se três questões que se relacionam ao estabelecimento de metas educacionais, à qualidade do ensino e à aprendizagem dos alunos. 
Gráfico 6 - Nesta escola e neste ano, indique a frequência com que...

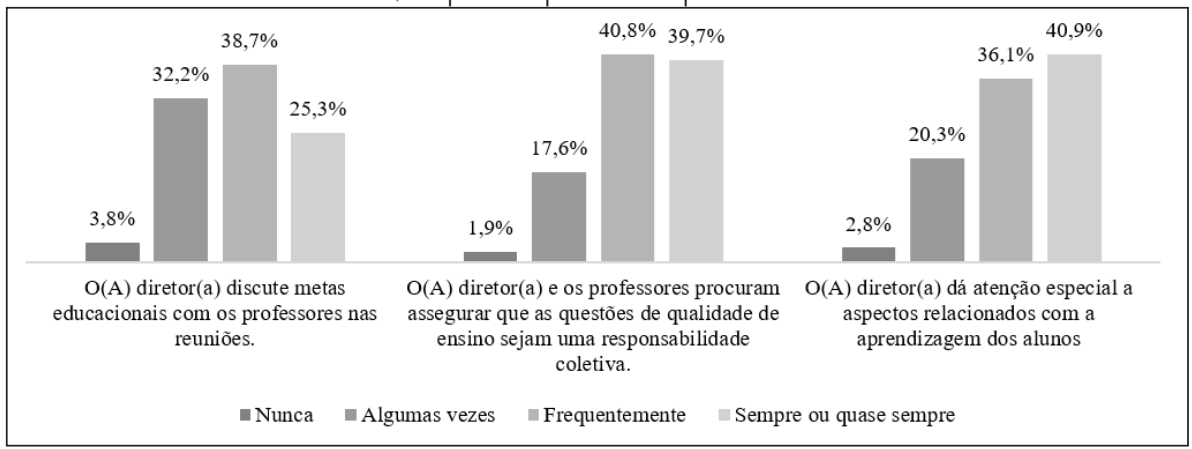

Fonte: os autores.

Para 64\% dos professores, frequentemente, sempre ou quase sempre o diretor discute sobre metas educacionais nas reuniões. Esse fato tem relação com a quantidade de avaliações a que a rede escolar é submetida ano a ano - Saeb nos anos impares, Spaece, ${ }^{8}$ anualmente, e Sistema de Avaliação do Ensino Fundamental (SAEF), ${ }^{9}$ sete vezes por ano. Os resultados obtidos nessas avaliações são objeto de escrutínio por parte da secretaria municipal, órgãos intermediários e escolas, que a partir deles estabelecem metas de melhoria para os indicadores monitorados. Para $80,5 \%$ dos docentes, frequentemente, sempre ou quase sempre a direção e o corpo docente procuram assegurar que as questões de qualidade de ensino seja uma responsabilidade coletiva, enquanto $77 \%$ dos professores afirmam que frequentemente, sempre ou quase sempre a direção dá atenção especial a aspectos relacionados com a aprendizagem dos alunos.

Embora se perceba uma concentração da responsabilização pelos resultados da aprendizagem ao nível da escola, chama a atenção o engajamento dos diretores acerca da dimensão pedagógica da gestão escolar e a adesão dos professores aos mesmos propósitos.

No Gráfico 7 é perceptível o protagonismo da direção escolar com relação às possibilidades de aperfeiçoamento profissional dos docentes, às normas administrativas e a aspectos relacionados com a manutenção da escola. Do total de professores que respondeu, $68,1 \%, 86,6 \%$ e $83,3 \%$ afirmam que frequentemente, sempre ou quase sempre a direção está engajada nesse tipo de atividade. Essas demandas posicionam o diretor num estado de alerta

80 Sistema Permanente de Avaliação da Educação Básica do Ceará (Spaece), criado em 1992, consiste numa avaliação externa de larga escala e tem como principal objetivo realizar um diagnóstico da educação cearense a partir da avaliação de desempenho dos estudantes e de aplicação de questionários contextuais junto a diretores, professores e alunos. A partir de 2007 passou a ser aplicado anualmente.

9 O SAEF é um sistema implantado em 2013 pela Secretaria Municipal de Educação (SME) de Fortaleza, no qual são inseridos periodicamente os dados das avaliações internas diagnósticas produzidas pelo setor de avaliação dos Distritos de Educação e aplicadas pelas unidades escolares nos meses de fevereiro, abril, junho, agosto, setembro, outubro e novembro. 
constante, não só pela diversidade de tarefas, mas também pelas implicações burocráticas que envolvem, por exemplo, as normas administrativas e os aspectos relacionados à manutenção da escola.

Gráfico 7 - Nesta escola e neste ano, indique a frequência com que...

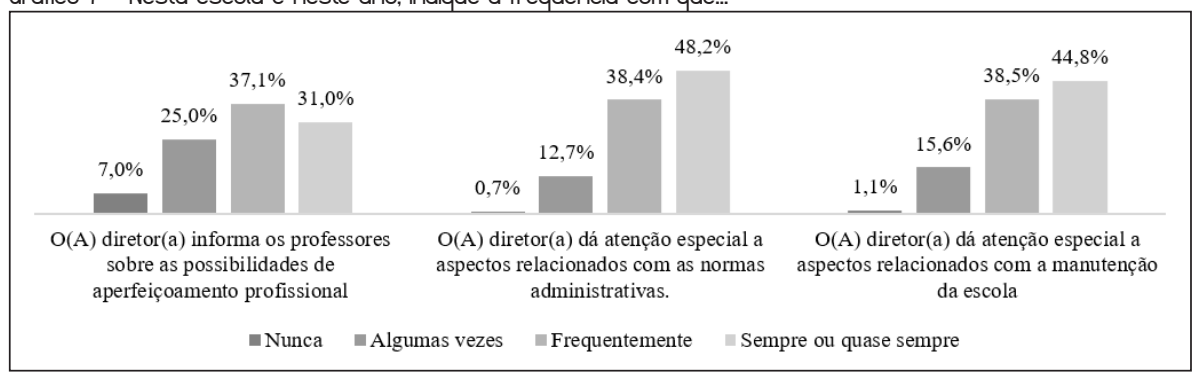

Fonte: os autores.

0 Gráfico 8 contêm respostas dos professores às questões relacionadas às interações pessoais e profissionais com a direção da escola e seus pares.

Gráfico 8 - Nesta escola e neste ano, indique a frequência com que...

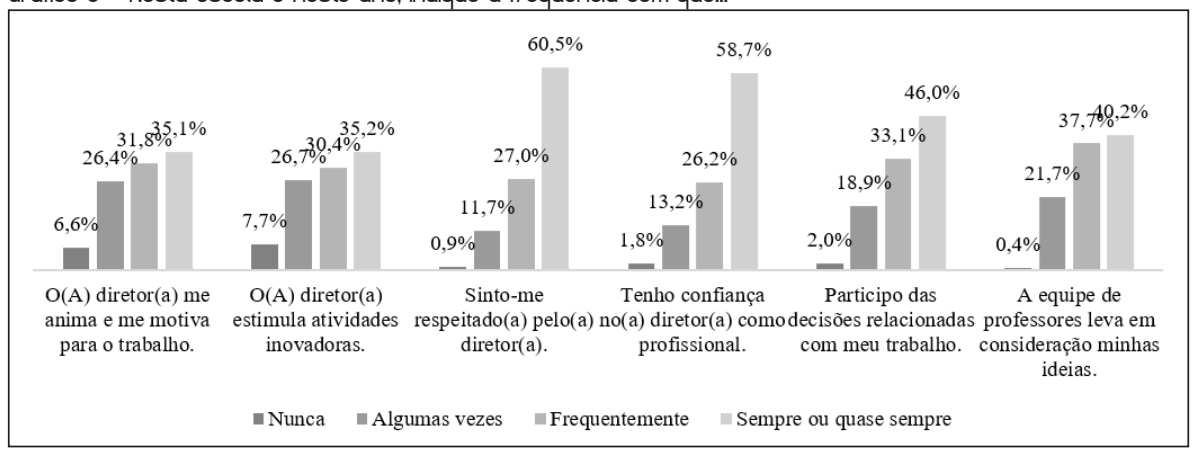

Fonte: os autores.

Os dados revelam um clima de respeito e confiança com relação ao diretor, uma vez que $87,5 \%$ e $84,6 \%$ dos professores afirmam que frequentemente, sempre ou quase sempre as relações são permeadas por esses valores. No que diz respeito à participação nas decisões relacionadas ao trabalho e à aceitação das ideias por parte da equipe docente, $79,1 \%$ e $77,2 \%$ dos professores afirmam que frequentemente, sempre ou quase sempre isso acontece. Os menores percentuais são obtidos na postura do diretor com relação à 
motivação para o trabalho docente $(66,9 \%)$ e no estímulo, por parte do diretor, a atividades inovadoras $(65,6 \%)$.

Depreende-se, assim, que nas escolas da rede municipal de Fortaleza prevalece um clima escolar permeado por relações interpessoais amistosas, pautadas no respeito e na confiança; que mais de $3 / 4$ dos docentes se sentem incluídos nas decisões relacionadas ao trabalho e reconhecem que suas ideias são respeitadas; e mais de $2 / 3$ reconhecem que 0 diretor motiva o trabalho docente e estimula inovações por parte dos professores.

\section{CONFRONTANDO AS PERCEPÇÕES DOS PROFESSORES E DOS DIRETORES}

0 Conselho de Classe é considerado uma instância de reconhecida importância e possibilidades para conhecimento e avaliação do trabalho pedagógico que se realiza no cotidiano das práticas escolares, uma vez que "[...] o conselho de classe é um local onde equipe pedagógica e professores devem desenvolver um processo de reflexão crítica que thes possibilitem perceber as influências de seu contexto sociocultural e questionar as visões tácitas do mundo." (GUERRA, 2006, p. 3).

Segundo Dalben (2010, p. 1), existem algumas características básicas que fazem o Conselho de Classe diferente de outros órgãos colegiados e que the conferem centralidade para o desenvolvimento do projeto pedagógico da escola. Essas características são: "a forma de participação direta, efetiva e em rede dos profissionais que atuam no processo pedagógico com os estudantes; a sua organização interdisciplinar; e a centralidade da avaliação da aprendizagem como foco de todo o trabalho dos conselhos."

No que concerne ao Conselho de Classe, uma estrutura colegiada de natureza pedagógica e avaliativa, os questionários contextuais indagam os diretores e os professores sobre a existência e a frequência de reuniões por ano. Importante destacar que desde sua origem o Conselho de Classe é considerado uma importante instância colegiada da escola (PAPI, 2015), está relacionado aos processos avaliativos (DALBEN, 2004, 2010; BRANDÃO; RAMOS; CRUZ, 2018) e é considerado um ".... espaço de reflexão coletiva sobre a prática pedagógica, na direção de permitir ressignificar as concepções de ensino, de aprendizagem e de avaliação." (BRANDÃO; RAMOS; CRUZ, 2018, p. 945).

Os dados obtidos junto aos dois grupos estão apresentados nos Gráficos 9 e 10. 
Gráfico 9 - Presença do Conselho de Classe e frequência de reuniões por ano, Diretores

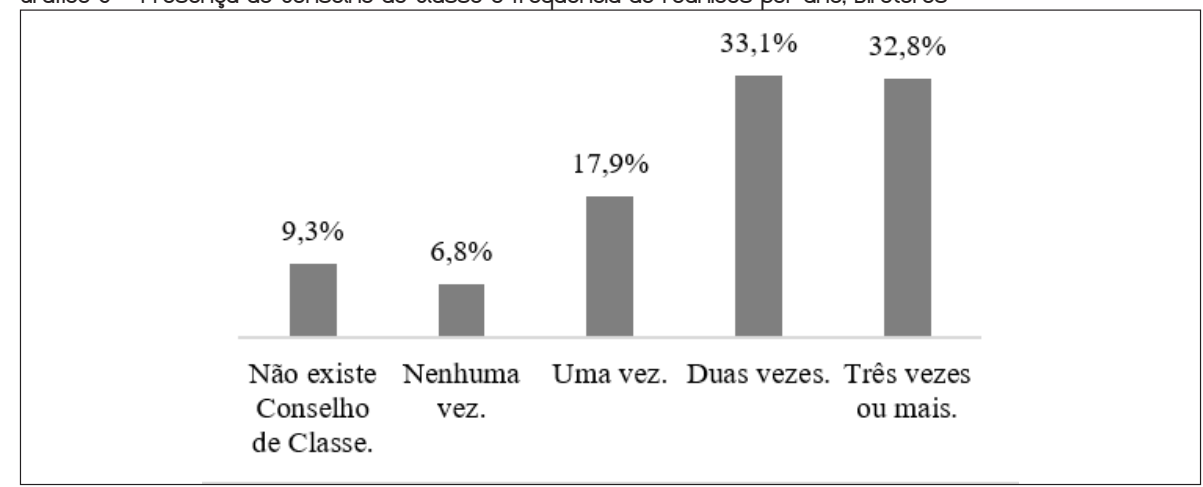

Fonte: os autores.

Gráfico 10 - Presença do Conselho de Classe e frequência de reuniões por ano, Professores

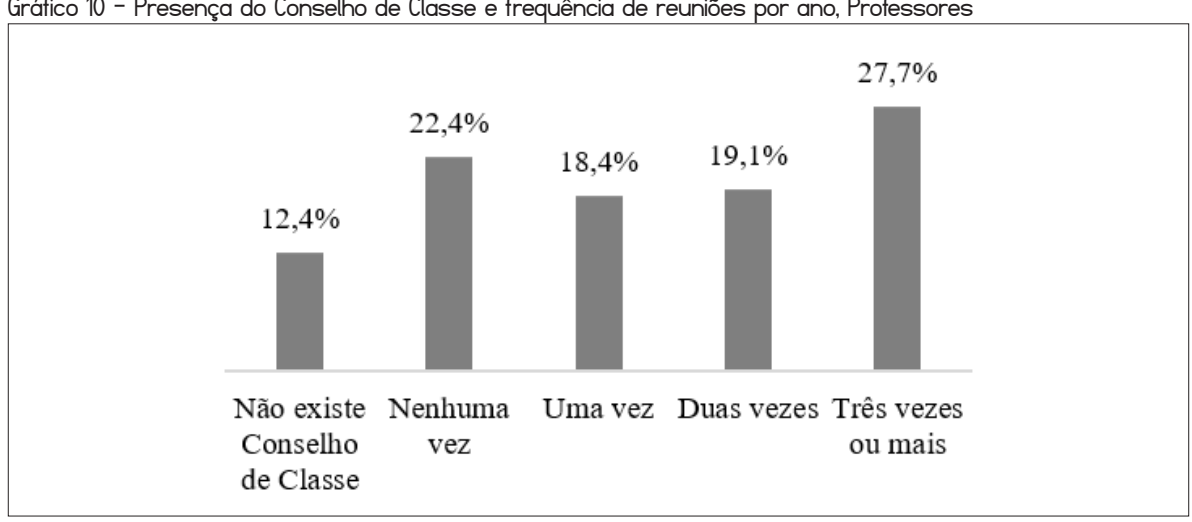

Fonte: os autores.

Para a mesma pergunta, a visão dos diretores se mostra substantivamente diferente daquela dos professores. Enquanto 32,8\% dos diretores afirmam que o Conselho de Classe se reúne três vezes ou mais por ano, $27,7 \%$ dos professores são da mesma opinião; $33,1 \%$ dos diretores informam que o Conselho de Classe se reúne duas vezes por ano, e apenas 19,1\% corroboram essa informação. Sobre a inexistência do Conselho de Classe, são $9,3 \%$ e $12,4 \%$ dos diretores e professores, respectivamente, enquanto o fato de não haver reunião foi apontado por $6,8 \%$ dos diretores e $22,4 \%$ dos professores. 0 u seja, os diretores apresentam uma visão mais otimista do que os professores, que são os responsáveis, por excelência, pela existência dos Conselhos de Classe. Para dirimir dúvidas sobre essas discrepâncias, procurou-se calcular o coeficiente de correção $0^{10}$ entre os dois grupos de

10 A função Correl retorna o coeficiente de correlação e é usada para determinar a relação entre duas propriedades. 0 coeficiente de correlação varia de +1 a -1 . Se a correlação é positiva significa que, se os valores em uma matriz estiverem 
respostas e chegou-se a um valor positivo de 0,2383 , o que indica que há uma correlação fraca entre elas, que pode ser considerada desprezivel, ou seja, há uma baixa correlação entre as respostas dos professores e diretores.

Uma outra questão comum aos diretores e professores diz respeito a como se realizou a elaboração do projeto pedagógico na escola. Os dados sobre as escolas de Fortaleza estão apresentados nos Gráficos 11 e $२$.

Gráfico 11 - Elaboração do Projeto Pedagógico na escola na visão dos diretores

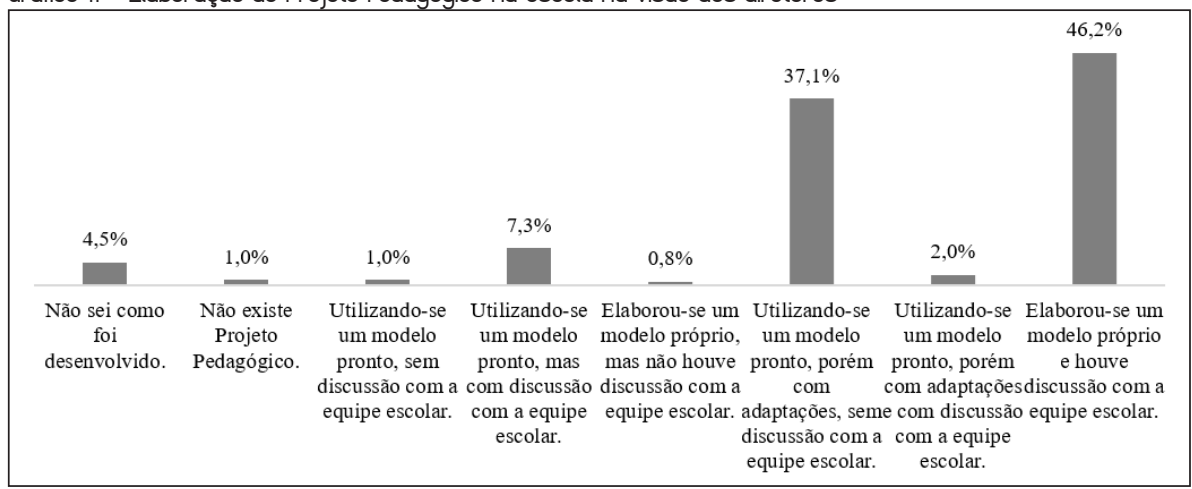

Fonte: os autores.

Gráfico 12 - Elaboração do Projeto Pedagógico na escola na visão dos professores

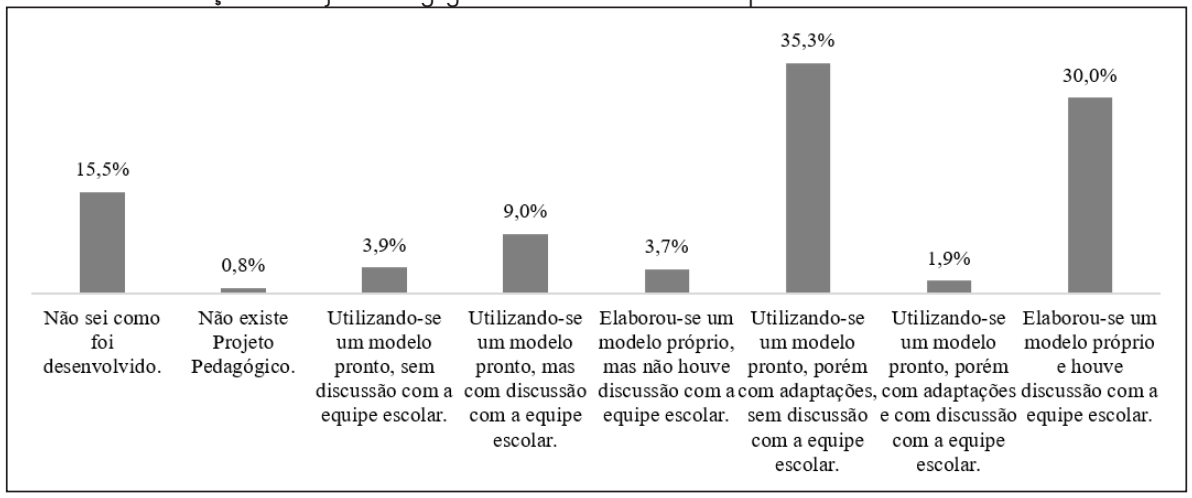

Fonte: os autores.

aumentando, os valores na outra matriz aumentarão também. Se a correlação é negativa significa que quando os valores de uma matriz aumentam, os da outra diminuem. Um coeficiente de correlação mais próximo de 0 indica nenhuma ou pouca correlação. 
Pode-se constatar uma nítida discrepância entre as respostas de ambos os grupos de respondentes. Enquanto apenas 4,5\% dos diretores afirmam não saber como foi desenvolvido o projeto político-pedagógico da escola na qual está exercendo o cargo, 15,5\% dos professores desconhecem a informação. Dentre os diretores, $46,2 \%$ indicam que o projeto pedagógico foi elaborado por meio de um modelo próprio e em discussão com a equipe escolar, enquanto $30 \%$ dos professores é da mesma opinião. Considerando as divergências nas respostas dos dois grupos, procurou-se calcular o coeficiente de correlação e obtevese 0,9240 , evidenciando que há uma correlação forte entre as respostas dos diretores e professores.

Como bem pontua Souza (2010, p. 21),

[...] o PPP é uma coisa um tanto difusa, materialmente pouco elaborada e conhecida, mas simbolicamente tida como importante e, assim, os docentes tendem a afirmar a sua existência e forma democrática de construção porque sabem que isso é o que deles se espera.

No caso das escolas de Fortaleza, menos de 1/3 dos docentes corrobora a afirmação de Souza (2010). Sobre a elaboração do projeto político-pedagógico, o fato de 46,2\% dos diretores afirmarem que o fizeram a partir de um modelo próprio e em discussão com a equipe escolar evidencia um grau de engajamento e protagonismo no sentido de favorecer atitudes que apontam para uma maior participação da comunidade escolar nesse documento, considerado pela própria LDB como base fundamental da gestão democrática da escola pública.

\section{CONSIDERAÇÕES FINAIS}

Este artigo procurou mostrar que as discussões sobre a gestão democrática e participativa nas escolas públicas brasileiras se constituem ponto sobre o qual há acordos e divergências, gerando uma polissemia do termo que propicia um terreno fértil para interpretações e adequações por parte dos sistemas de ensino. Que, embora a legislação de Fortaleza sobre o tema seja posterior à publicação do PNE 2014-2024, não contempla a consulta pública à comunidade escolar, atendo-se a uma seleção pública e dando prerrogativas à Secretaria Municipal de Educação para o exercício do poder discricionário na indicação dos diretores. 
Os dados analisados a partir das questões presentes nos questionários contextuais do Saeb 2017 permitem esboçar alguns aspectos que orientam a gestão escolar da rede municipal de Fortaleza, quais sejam: a existência de Conselhos Escolares compostos por todos os segmentos da comunidade escolar se faz presente em mais de 3/4 da rede; cerca de 2/5 dos diretores afirmam haver interferências de atores externos em sua gestão; e aproximadamente $4 / 5$ dos diretores estão frequentemente discutindo medidas com os professores para melhorar o ensino e a aprendizagem dos alunos.

Os professores, por sua vez, apresentam uma visão muito positiva sobre a gestão escolar, tanto no que diz respeito à dimensão pedagógica quanto a aspectos administrativos e de relações interpessoais. No entanto, quando se comparam as respostas das duas questões comuns aos questionários, observam-se discrepâncias que precisam ser melhor investigadas.

A partir dos resultados analisados é possivel levantar algumas questões que investigações mais detalhadas podem ajudar a esclarecer: a) em que medida a seleção pública e posterior indicação para o cargo de diretor por parte da Secretaria Municipal de Educação padroniza a gestão escolar? E mais que isso, unifica o discurso em torno de uma gestão por resultados? b) a forte política de accountability implementada pelo Governo do Estado com ampla repercussão nas redes municipais contribuiu para a gestão escolar se concentrar na aprendizagem discente? c) que mecanismos de gestão estão promovendo a integração da equipe escolar e propiciando um clima de confiança e respeito junto aos professores em mais de 4/5 das escolas? d) qual a natureza de participação dos Conselho Escolar e Conselho de Classe? Funcionam como mecanismos de participação efetiva ou se identificam mais como fator de coesão de consensos?

0 estudo mostra, também, que os questionários contextuais do Saeb representam importantes bases de dados que, analisadas, fornecem informações valiosas sobre situações vivenciadas pelos sistemas educativos e escolas, ajudando a avaliar e orientar políticas públicas. E podem vir a fornecer pistas preciosas sobre novas pesquisas qualitativas para investigar aspectos específicos de interesse de pesquisadores ou de órgãos públicos.

\section{REFERÊNCIAS}

ALCANTARA, L. G. de. Apresentação. In: HOLANDA, M. C. (org.) Ceará: a prática de uma gestão pública por resultados. Fortaleza: IPECE, 2006. p. 5-7.

ALVES, J. B. P. A trajetória, possibilidades e limites dos conselhos de escola na rede municipal de Vitória-ES. 2005. Dissertação (Mestrado em Educação) - Universidade Federal Fluminense, Niterói, RJ, 2005. Disponível em: www.uff.br/pos_educacao/joomla/ images/stories/Teses/joaoalves05.pdf. Acesso em: 13 maio 2019. 
ARAÚJJ, M. C. M. Gestão Escolar. Curitiba: IESDE, 2009.

ARAÚJO, S. de; CASTRO, A. M. D. A Gestão educativa gerencial: superação do modelo burocrático? Ensaio: Aval. Pol. Públ. Educ., Rio de Janeiro, v. 19, n. 70, p. 81-106, mar. 2011. Disponível em: http://www. scielo.br/pdf/ensaio/v19n70/v19n70a06.pdf. Acesso em: 20 jul. 2018.

BÄCKMAN, E;; TRAFFORD, B. Governança democrática das escolas. Lisboa: Conselho Nacional de Educação; Conselho da Europa, 2007. Disponivel em: http://www.edchreturkey-eu.coe.int/Source/ Resources/Pack/BookDemgovernchoolspublic_por.pdf. Acesso em: 20 jun. 2019.

BARROSO, J. 0 reforço da autonomia das escolas e a flexibilização da gestão escolar em Portugal. In: FERREIRA, N. S. C. (org.). Gestão democrática da educação: atuais tendências, novos desafios. 4. ed. São Paulo: Cortez, 2003. p. 11-32.

BORDIGNON, G. Gestão da educação no município: sistema, conselho e plano. São Paulo: Instituto Paulo Freire, 2009.

BRANDÃO, M. M. R. T.; RAMOS, K. M. da C.; CRUZ, F. M. L. Conselho de Classe: sentidos compartilhados por professores. Perspectiva, Florianópolis, v. 36, n. 3, p. 943-960, out. 2018. Disponível em: https:// periodicos.ufsc.br/index.php/perspectiva/article/view/2175-795X.2018v36n3p943. Acesso em: 7 maio 2020.

BRASIL. Constituição. República Federativa do Brasil de 1988. Brasilia, DF: Senado Federal, 5 out. 1988.

BRASIL. Lei n. 13.005, de 25 de junho de 2014. Aprova o Plano Nacional de Educação - PNE e dá outras providências. Diário Oficial da União, Brasília, DF, 26 jun. 2014. Disponível em: http://www.planalto.gov. br/ccivil_03/_ato2011-2014/2014/lei/113005.htm. Acesso em: 17 out. 2018.

CABRAL NETO, A.; CASTRO, A. M. D. A Gestão Educacional na América Latina: delineamentos e desafios para os sistemas de ensino. In: EYNG, A. M.; GISI, M. L. (org.). Política e gestão da educação superior: desafios e perspectivas. ljuí, RS: Unijuí, 2007. p. 15-47.

CANO, F. et al. Estudios sobre eficacia escolar en lberoamérica: 15 buenas investigaciones. Bogotá, Colombia: Convenio Andrés Bello, 2006. Disponivel em: https://web.oas.org/childhood/ES/Lists/Recursos\%20\%20Estudios\%20e\%20Investigaciones/Attachments/21/14.\%20Estudios\%20sobre\%20eficacia\%20 escolar\%20en\%20lberoam\%C3\%A9rica.pdf. Acesso em: 15 dez. 2019.

CARVALHO, E. J. G. de. Reestruturação produtiva, reforma administrativa do estado e gestão da educação. Educ. Soc., Campinas, v. 30, n. 109, p. 1139-1166, set./dez. 2009. Disponivel em: http://www.scielo. br/pdf/es/v30n109/v30n109a11.pdf. Acesso: 9 jul. 2018. 
CEARÁ. Lei n. 14.023, de 17 de dezembro de 2007. Modifica dispositivos da Lei $n^{\circ} 12.612$, de 7 de agosto de 1996, que define critérios para distribuição da parcela de receita do produto e arrecadação do imposto sobre operações relativas à circulação de mercadorias e sobre prestações de serviços de transporte interestadual e intermunicipal e de comunicação - ICMS, pertencente aos municípios e dá outras providências. Diário Oficial do Estado, Fortaleza, CE, ano X, n. 239, cad. 12, p. 1, 19 dez. 2007. Disponivel em: https://www.al.ce.gov.br/legislativo/legislacao5/leis2007/14023.htm. Acesso em: 13 set. 2018.

CERQUEIRA, D. M. de A. Democratização da gestão escolar: política, lei e ação. Revista Gestão em Ação, Salvador, v. 1, n. 1, p. 5-56, jul./dez. 2000. Disponivel em: http://www.gestaoemacao.ufba.br/revistas/ gav3n200.PDF. Acesso em: 11 nov. 2018.

DALBEN, A. I. L. de F. Conselho de classe e avaliação: perspectivas na gestão pedagógica da escola. Campinas: Papirus, 2004.

DALBEN, A. I. L. de F. Conselho de Classe. In: OLIVEIRA, D. A.; DUARTE, A. M. C.; VIEIRA, L. M. F. Dicionário: trabalho, profissão e condição docente. Belo Horizonte: UFMG, 2010. Disponivel em: http://www.gestrado.net.br/ pdf/103.pdf. Acesso em: 23 set. 2018.

DALE, R. A sociologia da educação e o Estado após a globalização. Educ. Soc., Campinas, v. 31, n. 113, p. 1099-1120, dez. 2010. Disponivel em: http://www.scielo.br/scielo.php?script=sci_arttext\&pid=S0101-73302010000400003\&lng=en\&nrm=iso. Acesso em: 21 abr. 2020.

DAY, C. et al. The impact of school leadership on pupil outcomes - Final Report. London: University of Nottingham, jun. 2009. Disponivel em: https://dera.ioe.ac.uk/ १1329/1/DCSF-RR108.pdf. Acesso em: 13 dez. 2019.

DOURADO, L. F. A escolha de dirigentes escolares: politicas e gestão da educação. In: FERREIRA, N. S. C. Gestão Democrática da Educação: atuais tendências, novos desafios. 8. ed. São Paulo: Cortez, 2013. p. 95-117.

DRESCHER, C. H. P. A importância do Conselho Escolar para a gestão democrática da escola. 2014. Monografia (Especialização Latu Sensu em gestão Educacional) - Universidade Federal de Santa Maria, Agudo, RS, 2014. Disponivel em: https://repositorio.ufsm.br

/bitstream/handle/1/3128/Drescher_Carla_Hulda_Pfeifer.pdf? sequence=1. Acesso em: 25 maio 2019.

FORNO, M. R. G. D.; FERREIRA, N. S. C.; MARKOWICZ, D. Gestão da educação e formação de professores: experiências de uma escola estadual do paraná. In: ANPED SUL, 9., 2012, Caxias do Sul. Anais [...] Caxias do Sul, 2012. Disponível em: http://www.ucs.br/etc/conferencias/index.php/anpedsul/9anpedsul/ paper/viewFile/2536/504. Acesso em: 15 set. 2018.

FORTALEZA. Lei Complementar n. 169/2014, de 15 de setembro de 2014. Diário Oficial do Município, Fortaleza, CE, ano LXI, n. 15.361, p. 1-9, 15 set. 2014. Disponivel em: https://diariooficial.fortaleza. ce.gov.br/download-diario.php?objectld=wor kspace://SpacesStore/702ae419-a79c-40e6-b3b24dcf4ba453aa;1.1\&numero=15361. Acesso em: 13 set. 2018. 
FORTALEZA. Lei n. 9.317/2007, de 14 de dezembro de 2007. Institui o Sistema Municipal de Ensino de Fortaleza e reformula o Conselho Municipal de Educação. Diário Oficial do Município, Fortaleza, CE, ano LV, n. 13.719, p. 1-3, 14 dez. 2007. Disponível em: https://diariooficial.fortaleza.ce.gov.br/download-diario. php?objectld=workspace://SpacesStore/b1dfc748-231d-4e3e-8735-65a5a2dfed14;1:1\&numero=13719. Acesso em: 17 maio 2020.

FORTALEZA. Lei n. 10.371, de 24 de junho de 2015. Plano Municipal de Educação 2015-2025. Diário Oficial do Município, Fortaleza, CE, ano LXI, n. 15.549, p. 1-51, 24 jun. 2015. Disponível em: https://diariooficial. fortaleza.ce.gov.br/download-diario.php?objectld=workspace://SpacesStore/98d78114-2795-48c2-b624-555082 c02555; 1.1\&numero=15549. Acesso em: 13 set. 2018.

FREIRE, P. Professora sim, tia não: cartas a quem ousa ensinar. São Paulo: Ed. Olho d'Água, 1997.

FUJTTA, I. K. A gestão participativa na educação pública brasileira: desafios na implantação e o perfil do gestor. Revista ENIAC Pesquisa, Guarulhos, SP: Centro Universitário ENIAC, v. 4, n. 2, jul./dez. 2015. Disponivel em: https://ojs.eniac.com.br/index.php/EniacPesquisa/ article/download/260/pdf. Acesso em: 15 set. 2018.

GADOTTI, M. Gestão democrática com participação popular no planejamento e na organização da educação nacional. In: CONFERÊNCIA NACIONAL DE EDUCAÇÃO - CONAE, 2014, Brasília, DF. Anais [...] Brasília: Fórum Nacional de Educação (FNE)/MEC, 2014. p. 1-25. Disponível em: http://conae2014.mec.gov.br/ images/pdf/artigogadotti_final.pdf. Acesso em: 13 ago. 2018.

GUERRA, M. G. G. Conselho de classe: que espaço é esse? 2006. Dissertação (Mestrado em Linguística Aplicada e Estudos da Linguagem) - Pontifícia Universidade Católica de São Paulo, São Paulo, 2006. Disponivel em: https://sapientia.pucsp.br/handle/handle/13820. Acesso em: 22 ago. 2018.

HOLANDA, M. C. et al. 0 Modelo aplicado de gestão pública por resultados (GPR) no Estado do Ceará. In: HOLANDA, M. C. (org.) Ceará: a prática de uma gestão pública por resultados. Fortaleza: IPECE, 2006. p. 55-76. Disponivel em: https://www.jpece.ce.gov.br/ wp-content/uploads/sites/45/2015/02/CearaGPR.pdf. Acesso em: 7 jun. 2018.

IBGE. Estimativas da população residente com data de referência $1^{\circ}$ de julho de 2019. Rio de Janeiro: IBGE, 2019. Disponível em https://cidades.ibge.gov.br/brasil/ce/fortaleza/panorama. Acesso em: 10 ago. 2019.

INEP. Sinopse Estatística da Educação Básica 2018. Brasilia: Inep, 2019. Disponivel em: http://portal.inep. gov.br/sinopses-estatisticas-da-educacao-basica. Acesso em: 10 maio 2019.

JARL, M.; FREDRIKSSON, A.; PERSSON, S. New public management in public education: a catalyst for the professionalization of Swedish school principals. Public Administration, n. 90, p. 429-444, 2012. Disponível em: https://onlinelibrary.wiley.com/doi/abs/10.1111/j.1467-9299.2011.01995.x. Acesso em: 20 ago. 2019. 
LEITHWOOD, K. ¿̇Cómo liderar nuestras escuelas? Aportes desde la investigación. Salesianos, Santiago de Chile: Fundación Chile, 2009. Disponivel em: http://repositorio.minedu.gob.pe/bitstream/handle/ MINEDU/5428/C\%25C3\%25B3mo\%20liderar\%20nuestras\%20escuelas\%20Aportes\%20desde\%20la\%20 investigaci\%25C3\%25B3n.pdf? sequence=1\&isAllowed=y. Acesso em: 14 abr. 2019.

LIMA, L. C. Organização escolar e democracia radical: Paulo Freire e a governação democrática da escola pública. 5. ed. São Paulo: Cortez, 2013.

MENDIZÁBAL, C. Á. et al. Transferencias directas a escuelas: reflexiones sobre prácticas en América Latina. 1. ed. Buenos Aires: IPE-Unesco, 2016. Disponível em: https://unesdoc.unesco.org/ark:/48223/ pf0000246258. Acesso em: 15 ago. 2019.

MENDONÇA, E. F. Estado patrimonial e gestão democrática do ensino público no Brasil. Educ. Soc., Campinas, SP: Unicamp, v. 22, n. 75, p. 84-108, ago. 2001. Disponivel em: http://www.scielo.br/ scielo. php?script=sci_arttext\&pid=S0101-73302001000200007 \&lng=en\&nrm=iso. Acesso em: 2 jun. 2020.

MURILLO, F. J. (coord.). Avances en democracia y liderazgo distribuido en educación: actas del II Congreso Internacional de Liderazgo y Mejora de la Educación. Madri-Spain: RLME, 2018. Disponível em: http://www.rinace.net/Javier.Murillo/Avancesen_Democracia_y_Liderazgo_Distribuido.pdf. Acesso em: 24 abr. 2019.

NARDI, E. L.; BOIAGO, P. F. S. Gestão Democrática do Ensino Público: sobre a produção em periódicos da área da educação (1996-2015). Revista Práxis Educacional, Vitória da Conquista-Bahia: Edições UESB, v. 14, n. 27, p. 335-365, jan./mar. 2018. Disponivel em: http://periodicos2.uesb.br/index.php/praxis/ article/view/2930. Acesso em: 23 jul. 2018.

OECD. TALIS - Teaching and Learning International Survey. [S. l.: Instituto Nacional de Estudos e Pesquisas Educacionais Anísio Teixeira, 2014. Disponivel em: http://www.oecd.org/education/talis/. Acesso em: 21 abr. 2019.

OLIVEIRA, A. C. P. de; CARVALHO, C. P. de. Gestão escolar, liderança do diretor e resultados educacionais no Brasil. Rev. Bras. Educ., Rio de Janeiro: ANPEd, v. 23, p. e230015, 2018. Disponível em: http://www. scielo.br/scielo.php?script=sci_arttext\&pid=S1413-24782018000100211\&lng=en\&nrm=iso. Acesso em: 7 abr. 2019.

OLIVEIRA, A. C. P.; GIORDANO, E. 0 perfil dos diretores das escolas públicas no Brasil. Educação On-Line, Rio de Janeiro: PUC-Rio, v. 13, n. 27, p. 49-72, 2018. Disponível em: http://educacaoonline.edu.puc-rio.br/ index.php/eduonline/article/view/376. Acesso em: 14 ago. 2019.

PAPI, S. de 0. G. Conselho de classe: que colegiado é esse? Estudos em Avaliação Educacional, São Paulo: FCC, v. 26, n. 62, p. 480, 2015. Disponível em: http://publicacoes.fcc.org.br/ojs/index.php/eae/ article/view/2931. Acesso em: 24 maio 2019. 
PENA, A. C.; SOARES, T. M. Fatores de liderança escolar e sua relação com o desempenho. Um estudo com diretores de escolas da rede pública de Minas Gerais/Brasil. Revista lberoamericana sobre Calidad, Eficacia y Cambio en Educación (REICE), Madri -Espanha: UAM, v. १2, n. 5, p. 5-8, 2014. Disponível em: https://revistas.uam.es/ index.php/reice/article/view/2827. Acesso em: 1 jun. 2020.

PEREIRA, J. M. M. Metamorfoses da política de ajuste estrutural do Banco Mundial (1980-2014). Sociologias, Porto Alegre, v. 19, n. 44, p. 390-422, jan. 2017. Disponível em: http://www.scielo.br/scielo. php?script=sci_arttext\&pid=S1517-452220170 00100390\&lng=en\&nrm=iso. Acesso em: 5 dez. 2019.

RIBEIRO, S. A. C. C. 0 perfil de gestão e o estilo de liderança de um diretor de uma organização educativa: quadros de referência de diferentes países. In: GALEGO, C.; RICARDO, M. M. C.; TEODORO, A. (org.). A Educação Comparada para além dos números: contextos locais, realidades nacionais e processos transnacionais. Lisboa, Portugal: CeiED/SPC-SC, 2017. v. 4. p. 238-234. Disponivel em: http://www.ceied. uluso fona.pt/pt/download/04-a-educacao-comparada-para-alem-dos-numeros-contextos-locais-realidades-nacionais-e-processos-transnacionais/. Acesso em: 13 jul. 2019.

RODRÍGUEZ-RUIZ, B.; MARTINEZ-GONZALEZ, R.-A.; RODRIGO LOPEZ, M. J. Dificuldades das famílias em participar de centros escolares. Revista Latino-americana de Educação Inclusiva, Santiago, Chile, v. 10, n. 1, p. 79-98, 2016. Disponivel em: https://scielo.conicyt.cl/scielo.php? script=sci_arttext\&pid $=$ S0718-73782016000100005 \&lng=n\&nrm=iso. Acesso em: 16 mar. 2019.

ROSAR, M. de F. F. A municipalização como estratégia de descentralização e de desconstrução do sistema brasileiro. In: OLIVEIRA, D. A. (org.). Gestão democrática da educação: desafios contemporâneos. 11. ed. Petrópolis, RJ: Vozes, 2015. p. 105-139.

SECRETARIA MUNICIPAL DE DESENVOLVIMENTO ECONÔMICO. Desenvolvimento Humano, por Bairro, em Fortaleza. Fortaleza: SMDE, 2014. Disponivel em: https://pt.calameo.com/read/0032553521353dc27b3d9. Acesso em: 20 jun. 2019.

SILVA, J. J. C. Gestão escolar participada e clima organizacional. Gestão em Ação, Salvador, v. 4, n. 2 , p. 49-59, jul./dez. 2001. Disponível em: http://www.gestaoema cao.ufba.br/revistas/gav4n201.PDF. Acesso em: 23 abr. 2019.

SOUZA, Â. R. de. As condições de democratização da gestão da escola pública brasileira. Ensaio: aval. pol. públ. educ., Rio de Janeiro, v. 27, n. 103, p. 271-290, jun. 2019. Disponível em: http://www.scielo. br/scielo.php?script=sci_arttext\&pid=S0104-4036201900 0200271\&lng=en\&nrm=iso. Acesso em: 2 jun. 2020.

SOUZA, Â. R. de. A perspectiva dos docentes paranaenses sobre a gestão da Escola Básica. Revista Pedagógica, Chapecó, v. 2, n. 25, p. 17-33, 2010. Disponível em: https://bell.unochapeco.edu.br/revistas/index.php/pedagogica/article/view/1215. Acesso em: 13 jul. 2018.

SOUZA, Â. R. de; PIRES, P. A. G. As leis de gestão democrática da Educação nos estados brasileiros. Educar em Revista, v. 34, n. 68, p. 65-87, 2018. Disponível em: http://www.scielo.br/pdf/er/ v34n68/0104-4060-er-34-68-65.pdf. Acesso em: 23 out. 2018. 
STÊNICO, J. A. de G.; ADAM, J. M.; PAES, M. S. P. As políticas de descentralização da gestão escolar no Brasil. Revista lberoamericana de Educación, v. 69, p. 91-108, 2015. Disponível em: https://rieoei.org/ historico/documentos/rie69a04.pdf. Acesso em: 16 maio 2018.

VEIGA, I. P. A. Projeto Político-Pedagógico, Conselho Escolar e Conselho de Classe: instrumentos da organização do trabalho. Revista Retratos da Escola, Brasília, DF: CNTE, v. 3, n. 4, p. 163-171, jan./jun. 2009. Disponivel em: http://retratosdaescola.emnuvens.com.br/rde/article/view/109/298. Acesso em: 16 mar. 2019.

VIEIRA, S. L.; VIDAL, E. M. Gestão Democrática da Escola no Brasil: desafios à implementação de um novo modelo. Revista lberoamericana de Educación, v. 67, n. 1, p. 19-38, 2015. Disponível em: https:// rieoei.org/historico/documentos/rie67a01.pdf. Acesso em: 25 out. 2018.

VIEIRA, S. L.; VIDAL, E. M. Liderança e gestão democrática na educação pública brasileira. Revista Eletrônica de Educação, v. 13, n. 1, p. 11-25, jan./abr. 2019. Disponivel em: http://www.reveduc.ufscar. $\mathrm{br} /$ index.php/reveduc/article/view/3175. Acesso em: 20 jul. 2019.

VIEIRA, S. L.; VIDAL, E. M. Perfil e formação de gestores escolares no Brasil. Dialogia, n. 19, p. 47-66, jan./jun. 2014. Disponivel em: https://periodicos.uninove.br/index.php?.jour nal=dialogia\&page=article\&op =view\&path\%5B\%5D=4984. Acesso em: 21 nov. 2019.

WEINSTEIN, J.; MUÑOZ, G.; HERNÁNDEZ, M. (coord.). El liderazgo escolar en América Latina y el Caribe. Un estado del arte en base a ocho sistemas escolares de la región. Santiago, Chile: Oficina Regional de Educación para América Latina y el Caribe, 2014. Disponivel em: http://www.unesco.org/new/es/ media-services/single-view-tv-release/news/el_liderazgo_escolar_en_america_latina_y_el_caribe/. Acesso em: 12 out. 2019.

WEINSTEIN, J.; MUÑOZ, G. (coord.). Liderazgo en escuelas de alta complejidad sociocultural: diez miradas. 1. ed. Santiago de Chile: Ediciones Universidad Diego Portales, 2019. Disponível em: www.academia. edu/42129213/Liderazgo_en_escuelas_de_alta_complejidad_socioeducativa. Acesso em: 5 maio 2019.

Endereço para correspondência: Avenida Dr. Silas Munguba, 1700, Itaperi, Fortaleza, Ceará, Brasil; eloisamvidal@yahoo.com.br

Roteiro, Joaçaba, U. 45, p. 1-28, jan./dez. 2020 | e23212 |E-ISSN 2177-6059 
